\title{
THE LICENSING EXPERIENCE OF THE MODULAR HIGH-TEMPERATURE GAS-COOLED REACTOR (MHTGR)
}

\author{
by \\ F.A. SILADY, J.C. CUNLIFFE, and L.P. WALKER
}

DISCLAIMER

This report was prepared as an account of work sponsored by an agency of the United States Government. Neither the United States Government nor any agency thereof, nor any of their employees, makes any warranty, express or implied, or assumes any legal liability or responsibility for the accuracy, completeness, or usefulness of any information, apparatus, product, or process disclosed, or represents that its use would not infringe privately owned rights. Reference herein to any specific commercial product, process, or service by trade name, trademark, manufacturer, or otherwise does not necessarily constitute or imply its endorsement, recommendation, or favoring by the United States Government or any agency thereof. The views and opinions of authors expressed herein do not necessarily state or reflect those of the United States Government or any agency thereof.

\section{SEPTEMBER 1988}

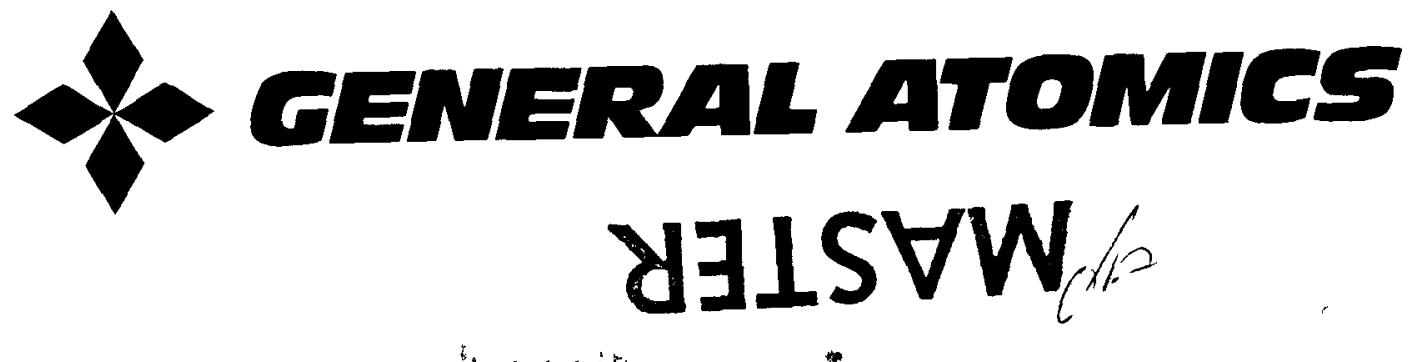




\title{
THE LICENSING EXPERIENCE OF THE MODULAR HIGH-TEMPERATURE GAS-COOLED REACTOR (MHTGR)
}

by
F.A. SILADY, J.C. CUNLIFFE * and L.P. WALKER **

This is a preprint of a paper to be presented at the IAEA TECHNICAL COMMITTEE MEETING ON DESIGN REQUIRE. MENTS, OPERATION AND MAINTENANCE OF GAS-COOLED REACTORS, San Diego, CA, on September 21-23, 1988.

- Bechtel Mational Inc.

** Stone \& Wehster Engineering Corporation

\author{
Work supported by \\ Department of Energy \\ Contract No. DE-AC03-88SF17367
}

GA PROJECT 7000

SEPTEMBER 1988
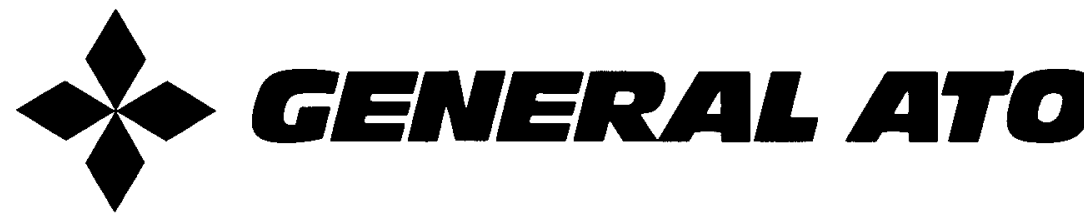


\section{DISCLAIMER}

This report was prepared as an account of work sponsored by an agency of the United States Government. Neither the United States Government nor any agency Thereof, nor any of their employees, makes any warranty, express or implied, or assumes any legal liability or responsibility for the accuracy, completeness, or usefulness of any information, apparatus, product, or process disclosed, or represents that its use would not infringe privately owned rights. Reference herein to any specific commercial product, process, or service by trade name, trademark, manufacturer, or otherwise does not necessarily constitute or imply its endorsement, recommendation, or favoring by the United States Government or any agency thereof. The views and opinions of authors expressed herein do not necessarily state or reflect those of the United States Government or any agency thereof. 


\section{DISCLAIMER}

Portions of this document may be illegible in electronic image products. Images are produced from the best available original document. 
THE LICENSING EXPERIENCE OF THE MODULAR HIGH-

TEMPERATURE GAS-COOLED REACTOR (MHTGR)

\author{
F. A. Silady \\ General Atomics \\ J. C. Cunliffe \\ Bechtel National, Inc. \\ L. P. Walker \\ Stone \& Webster Engineering Corporation
}

\title{
1. ABSTRACT
}

The MHTGR is an advanced reactor concept being developed under a cooperative program involving the U.S. Government, the nuclear industry, and the utilities. The design utilizes the basic HTGR features of ceramic fuel, helium coolant, and a graphite moderator. However, the specific size and configuration are selected to utilize the inherent characteristics of these materials to develop passive safety features that provide a significantly higher margin of safety than current generation reactors. The design meets the U.S. Environmental Protection Agency's Protective Action Guidelines at the site boundary, hence precluding the need for sheltering or evacuation of the public during any licensing basis event. This safe behavior is not dependent upon operator action and is insensitive to operator error.

The MHTGR Licensing Plan agreed to with the U.S. Nuclear Regulatory Commission (NRC) is discussed with particular attention to the framework of the preapplication review. The objective and scope of each key document prepared for the NRC review is presented. A summary is provided of the safety response to events challenging the functions relied on to retain radionuclides within the coated fuel particles. The regulatory interaction process and results are discussed through the NRC staff, NRC contractor, and ACRS reviews.

\section{INTRODUCTION}

In 1985 the U.S. DOE MHTGR program submitted a Licensing Plan (Reference 1) to the Nuclear Regulatory Comission that proposed an aggressive schedule of licensing activities prior to submittal of an application. Similarly, in 1986 the NRC issued the Advanced Reactor Policy (Reference 2) which encouraged the 
earliest possible interaction between the advanced reactor developers and the NRC and its staff. Both groups sought preapplication interactions to provide this early communication in the design and licensing process. This process, wherein the regulator worked with the designer to develop regulatory criteria and the designer worked with the regulator to set the conceptual design configuration, is in stark contrast to the previous procedure in which a complete preliminary design was presented to the regulator for approval. This paper describes the process that was proposed, the scope and objectives of the submittals, the manner in which they were reviewed, and the results to date of the NRC review.

\section{LICENSING PIAN}

The MHTGR licensing plan was developed in a manner that allows its framework to be applied to any advanced reactor. However, within this framework, which begins with the specification of generic Top Level Regulatory Criteria, there are areas of emphasis that are specific to the safety design of the MHTGR.

While this design utilizes basic features and inherent characteristics common to all HTGRs, the fundamental difference of the modular HTGR's safety design is that its size and configuration have been specifically selected to passively remove core heat thereby retaining radionuclides within the ceramic coated fuel particles. This is best illustrated in Figure 1 which shows chronologically the core sizes and geometries of the U.S. HTGRs and the corresponding maximum accident core temperature under conditions of loss of helium pressure and flow. Up until the development of the MHTGR, all previous designs sustained damage to a fraction of the silicon carbide (SiC) coated fuel. Only with the slender, annular core of $350 \mathrm{MW}$ themal rating does the geometry and size assure that sufficient heat could be removed passively by conduction and radiation to maintain fuel integrity.

Since the MHTGR's passive approach to radionuclide control is fundamentally different from existing reactors in the U.S., elements of the licensing plan cover the development of regulatory criteria. While the manner in which the criteria are derived is generic, the actual criteria are specific to the MHTGR. 
The MHTGR Licensing Plan identifies the licensing-related activities, administrative process, organizational responsibilities, and schedule necessary to support a U.S. Nuclear Regulatory Commission (NRC) review and approval of the Standard MHTGR. The objective of the Plan is to assure that necessary licensing activities are identified, planned and executed to a degree sufficient for the NRC to formally issue a Final Design Approval and certification for rulemaking for the Standard MHTGR.

For planning purposes, all licensing activities within the scope of the Plan are scheduled within one of two periods, namely the Preapplication and Application periods. Preapplication period licensing activities started in 1985, and have as an objective the issuance of an NRC Licensability Statement on the standard MHTGR. Application period activities will begin with the preparation of a Standard Safety Analysis Report (SSAR) and have as an objective the issuance by the NRC of a Final Design Approval and certification rulemaking for the Standard MHTGR Design.

Figure 2 displays the overall licensing logic for the Plan and identifies interfaces to the MHTGR Program schedule. The top two bars in the figure display the major elements of this Plan. The third bar displays critical program milestones.

Preapplication activities have implemented early interaction with the NRC and laid the groundwork for the Application activities. The objective of the Preapplication activity was to develop a Preliminary Safety Information Document (PSID) and other submittals to the NRC that led to an affimative licensability statement for the Standard MHTGR.

Conditioned on the conceptual stage of the standard MHTGR Design, the overall licensability statement should reach conclusions on the following questions: 
1. Is the Standard MHIGR Design reactor concept licensable?

2. Are the interfaces between the standard MHTGR Nuclear Island and the Energy Conversion Area and the site appropriately identified and characterized?

3. Are the top-level regulatory criteria acceptable and can they remain valid through Final Design Approval?

4. Is the methodology for proceeding from top-level regulatory criteria through risk assessments and other safety analysis to the deterministic licensing bases acceptable and can it remain valid through Final Design Approval?

5. Is the approach for emergency planning acceptable?

6. Is the proposed Regulatory Technology Development Plan adequate for the Standard MHTGR Final Design Approval?

7. Is the proposed Application procedure acceptable?

The conclusions drawn on these questions will provide a clear path and methodology for licensing an advanced Standard MFTGR Design, and will provide the NRC staff with reasonable assurance that the proposed design and its method of development and implementation will be successful.

\section{PREAPPLICATION SUBMITTALS}

During the Preapplication period, 15 licensing submittals have been made to the NRC for their review, including the Licensing Plan (Ref. 1), Top-Level Regulatory Criteria (Ref. 3), a Regulatory Technology Development Plan (Ref. 4), a 2-Volume Probabilistic Risk Assessment (Ref. 5), a 5-Volume PSID (Ref. 6), and an Emergency Planning Bases Report (Ref. 7). The objectives, scope, and results of the latter four submittals are described below. 
Regulatory Technology Development Plan (RTDP)

The purpose of the RTDP is to describe research and development programs, both planned or in progress, that generate technical infomation directly related to radionuclide control and retention for the Standard MFTGR.

The RTDP describes the requirements for data and the experimental tests that are needed to validate or confirm assumptions concerning the performance of equipment that limits radionuclide releases to acceptable limits. The RTDP describes the technology development required for radionuclide control in the following topical areas:

1. Fuel/fission products.

2. Graphite

3. Metals

4. Control materials

5. System/component tests

The RTDP will be expanded to include comitments made by DOE during the review process, such as a physics validation plan.

In each topical area, a sumary (status) of the existing data base is provided. Since the RTDP presents only the additional experimental programs intended to complete the data base, only brief sumaries of the existing information are given. Consequently, while the RTDP focuses on identifying technology plans yet to be completed, it should be recognized that most of the plans are backed by an existing comprehensive data base assembled from many years of international testing and operating experience with gas-cooled reactors. The additional data required for the MHTGR are for conditions specific to the MHTGR, to reduce uncertainties or to confirm expected results. 
The experimental programs described are those judged to be needed to complete the data base that assures that functions performed by design selections for the Standard MHTGR will be accomplished to ensure that radionuclide releases comply with the applicable regulatory criteria. In addition, in response to a user-specified requirement, the RTDP includes development activities that are judged to be needed to assure that the Protective Action Guides (Ref. 8) for exposure to airborne radioactive materials will not be exceeded at the plant's 425-m (0.26-mile) Exclusion Area Boundary. This requirement is imposed both to ensure a large margin in protection of the public from accidental releases and to avoid the need to involve civilian entities offsite with planning and training for public sheltering and evacuation.

The RTDP supports MHTGR development leading directly to a commercial plant. No prototype plant project is required for full scale safety tests. All experimental programs described can be performed in existing test facilities; no major new facilities are required. However, as shown in Figure 2, a private sector initiative leading to the first plant will be available to provide demonstration and experience prior to rulemaking for design certification. Startup and other tests supporting certification will be developed and submitted by DOE to NRC for approval.

\section{Probabilistic Risk Assessment (PRA)}

The objectives of the PRA are to:

1. Provide a means of characterizing the safety of the MHTGR such that the conceptual design can be evaluated in a logical fashion.

2. Provide the basis for the selection of the licensing basis events (LBES) evaluated in the PSID.

3. Evaluate a wide spectrum of events with offsite consequence to show compliance with Protective Action Guides (PAGs) at the exclusion area boundary in support of the Emergency Planning Bases report. 
4. Evaluate the risk to the public due to accident releases from the standard MHTGR to show compliance with the NRC safety goals.

The scope includes frequency and consequence assessments for a wide spectrum of events with frequencies greater than once in one hundred million years. An uncertainty evaluation for both the frequency and the consequence assessment is included.

Relative to the three levels of PRA defined in the NRC Procedures Guide (Ref. 9), this study is similar to the most comprehensive (level 3) study. However, the conceptual status of the design clearly limits both the breadth and depth of this assessment relative to a level 3 PRA for an existing plant.

The PRA assessment examined a broad event spectrum in order to identify events potentially dominant with respect to plant safety. From this examination, seven initiating events were selected for detailed evaluation:

1. Primary coolant leaks.

2. Loss of main cooling.

3. Seismic activity.

4. Loss of offsite power and inadvertent turbine trip.

5. Anticipated transients requiring reactor scram.

6. Control rod group withdrawal.

7. Steam generator leaks.

From these seven initiating events only primary coolant leaks, seismic activity, and steam generator leaks were found to result in potential offsite releases. The fission product release scenarios include depressurization of the reactor vessel under dry and wet core conditions with or without forced cooling. The accidents under dry conditions are initiated by primary coolant leaks and earthquakes. The accidents under wet conditions are initiated by the steam generator leaks. In these accidents the core cooling can be provided either by one of two forced cooling systems or by conduction through the reactor to remove heat out to the reactor cavity cooling system. 
The assessment results confirmed the selection of the Licensing Basis Events included within the PSID to be appropriate and consistent with this latest study. The PRA results confimed that even when a broad range of accidents that cover both a large cross section of initiating events and an extreme frequency spectrum is considered, the assessment of plant risk shows the MHTGR to be insensitive to failures in active, engineered systems. The frequency of potential radioactivity releases is essentially dictated by the failure of passive structures in the MHTGR. By virtue of its high reliance on passive features and inherent characteristics in this small MHTGR, the overall safety of the concept is shown to display unusually high levels of safety. The concept is shown to comply with the risk limits of the NRC Safety Goals and to do so with substantial margin. The MHTGR is even shown to satisfy the very stringent user-imposed requirement that PAG doses related to public evacuation and sheltering are not exceeded at the site Exclusion Area Boundary. PRA results demonstrate that releases with frequencies as low as $5 \times 10^{-7}$ per year would produce doses at the site boundary that are below the PAG sheltering thresholds of 1 Rem Whole Body and 5 Rem Thyroid.

\section{Preliminary Safety Information Document}

The objectives of the PSID are to:

1. Provide a basis for concluding that the Standard MHTGR concept is licensable.

2. Identify interfaces between the Nuclear Island, the Energy Conversion Area and a standard site.

3. Show compliance with dose and risk criteria.

The scope of the PSID is to document the licensing criteria and bases that have been established for the Standard MHTGR, the conceptual design that has been developed, and the analytical results which indicate that the criteria can be met. 
The design description provided in the PSID is focused on the Nuclear Island portion of the plant, though it does identify the interfaces with the remainder of the plant (referred to as the Energy Conversion Area) and a standard site. The Nuclear Island is considered to be that portion of the plant that has within its boundaries the standard reactor modules and "safety-related" buildings, structures, systems and components dedicated to assuring reactor shutdown, decay heat removal, fission product retention, and prevention of fuel chemical attack. Additionally, the Nuclear Island includes structures, systems and components not "safety-related," but which directly support reactor operation.

The safety analyses in the PSID evaluates the Anticipated operational occurrences and the Design Basis Events against the corresponding Top-Level Regulatory Criteria. As shown in Figure 3, each AOO and DBE meets the limiting regulatory criteria with orders of magnitude of margin.

\section{Emergency Planning Bases Report}

The objective of this report is to reach agreement with the NRC on the following points:

1. That the approach used to select emergency planning bases for the Standard MHTGR is consistent with and in instances more conservative than that used by regulatory agencies for existing reactors.

2. That emergency planning zones derived using this approach for the Standard MHTGR are appropriate.

3. That, since the plume exposure is encompassed by the plant exclusion area boundary, no plans or drills for rapid notification, sheltering, or evacuation of the public are required for the Standard MHTGR. 
The scope of the report includes a description of the approach used to determine emergency planning bases for the Standard MHTGR, as well as its application in determining emergency planning bases for the plume exposure pathway. The licensing basis events that are considered to form the emergency planning basis are defined, based on the PRA, and include the design basis events discussed in the PSID. The radiological consequences of the selected events are assessed for the plume exposure pathway using methods consistent with those used in the PRA. The determination of appropriate emergency planning bases is made in a manner consistent with, and in some instances more conservative than, the approach and rationale in NUREG-0396 (Ref. 10), which documents the planning bases for emergency planning for light-water nuclear power plants. The implications of the resultant EPZs on emergency planning for the Standard MFTGR are briefly discussed. Actual plans for responding to a radiological emergency are outside the scope of this report.

The PRA evaluates the events in the Emergency Planning Basis Region. Figure 3 shows that the EPBEs easily meet the NRC safety goal for individual latent fatality risk as well as the PAG for sheltering offsite. Even less frequent events are also evaluated in the PRA, and as Figure 3 shows, their consequences offsite also meet the PAG for sheltering. Several of the bounding events and their doses are discussed in Reference 11.

\section{REGULATORY INTERACTION PROCESS AND RESULTS}

Extensive interactions have taken place during the past five years with the NRC, its staff, and the Advisory Committee on Reactor Safeguards (ACRS). The NRC's Advanced Reactor Group has performed the technical review with input from their contractors and consultants, including Oak Ridge and Brookhaven National Laboratories.

Briefings have been held to familiarize NRC staff, the ACRS and various of its subcomittees with the MHTGR design and technology. From time to time the Commissioners have been collectively and individually briefed on the status of 
the interactions. The review of the design and technology has been based on numerous submittals to the NRC from 1985 to 1987, with working meetings almost monthly during 1987. In total, there have been more than 50 meetings over the last five years, with over 25 meetings with NRC's Advanced Reactor Group and over 10 meetings with the ACRS.

The formal review of the submittals by NRC and the ACRS has been completed. The NRC has drafted the Safety Evaluation Report (SER) on the MHTGR design. In this Preapplication period, the SER provides initial guidance to the designers. The SER reviews the design with an emphasis on the equipment relied on to meet regulatory criteria. Independent contractor evaluations of the response of the MHTIGR to off-normal events are included.

In general, the SER concludes that the MHTGR has the potential to have a high level of safety, is expected to exceed the safety level of current LWRs, and has the potential to meet or exceed the NRC Safety Goals. Particular aspects of the MHTGR design and licensing approach that have been found technically acceptable by the NRC reviewers include the absence of traditional pressure-retaining containment structure, the use of a mechanistic source term to determine site suitability, and the absence of the need for an offsite plan for evacuation or sheltering of the general public.

The SER was submitted to the Comissioners in August. It is under review by the ACRS, from whom a favorable letter is expected in september. The ACRS is expected to comment on the MHTGR containment system and the role of the operator, while focusing on generic Advanced Reactor Policy issues. The issuance of the SER will significantly influence the continued development of the MHTGR design, as well as the private initiative to market the MHTGR.

The preapplication interactions with the NRC have been very constructive and invaluable to the MHTGR program. The feedback has enabled the preliminary design to get underway with an understanding of the regulatory requirements for advanced reactors and of the specific areas of interest to the regulator. The MHTGR program looks forward to receiving a favorable SER and to continued productive interactions with the NRC. 


\section{REFERENCES}

1) "Licensing Plan for the Standard HTGR," DOE Report HTGR-85001, Rev. 3, February 1986.

2) U.S. Nuclear Regulatory Commission, "Policy for the Regulation of Advanced Nuclear Power Plants," Federal Register, Vol. 51, p. 24643, July 8, 1986.

3) "Top-Level Regulatory Criteria for the Standard HTGR," DOE Report DOE-HTGR-85002, Rev. 2, October 1986.

4) "Regulatory Technology Development Plan for the Standard Modular High-Temperature Gas-Cooled Reactor," DOE Report DOE-HTGR-86064, Rev. 1, August 1987.

5) "Probabilistic Risk Assessment for the Standard Modular HighTemperature Gas-Cooled Reactor," DOE Report DOE-HTGR-86011, Rev. 5, April 1988.

6) "Preliminary Safety Information Document for the Standard MHTGR," DOE Report HTGR-86024, through Amendment 9, April 1988.

7) "Emergency Planning Bases for the Standard MHTGR," DOE Report DOE-HTGR-87001, Rev. 1, August 1987.

8) "Manual of Protective Action Guides and Protective Actions for Nuclear Incidents," Environmental Protection Agency Report EPA-520/1-75-001, September 1975 (revised June 1980).

9) "PRA Procedures Guide," NRC Document NUREG/CR-2300, January 1983. 
10) "Planning Basis for the Development of state and Local Government Radiological Emergency Response Plans in Support of Light Wataer Reactor Nuclear Power Plants," U.S. Nuclear Regulatory Comission and U.S. Environmental Protection Agency Report, NUREG-0396: EPA-520/1-78-016, December 1978.

11) A. J. Neylan, presentation at GCRA Conference, San Diego, CA, September 20, 1988.

\section{ACKNOWLEDGEMENTS}

This paper was supported by the Department of Energy, San Francisco Operations Office Contract DE-AC03-88SF17367. 


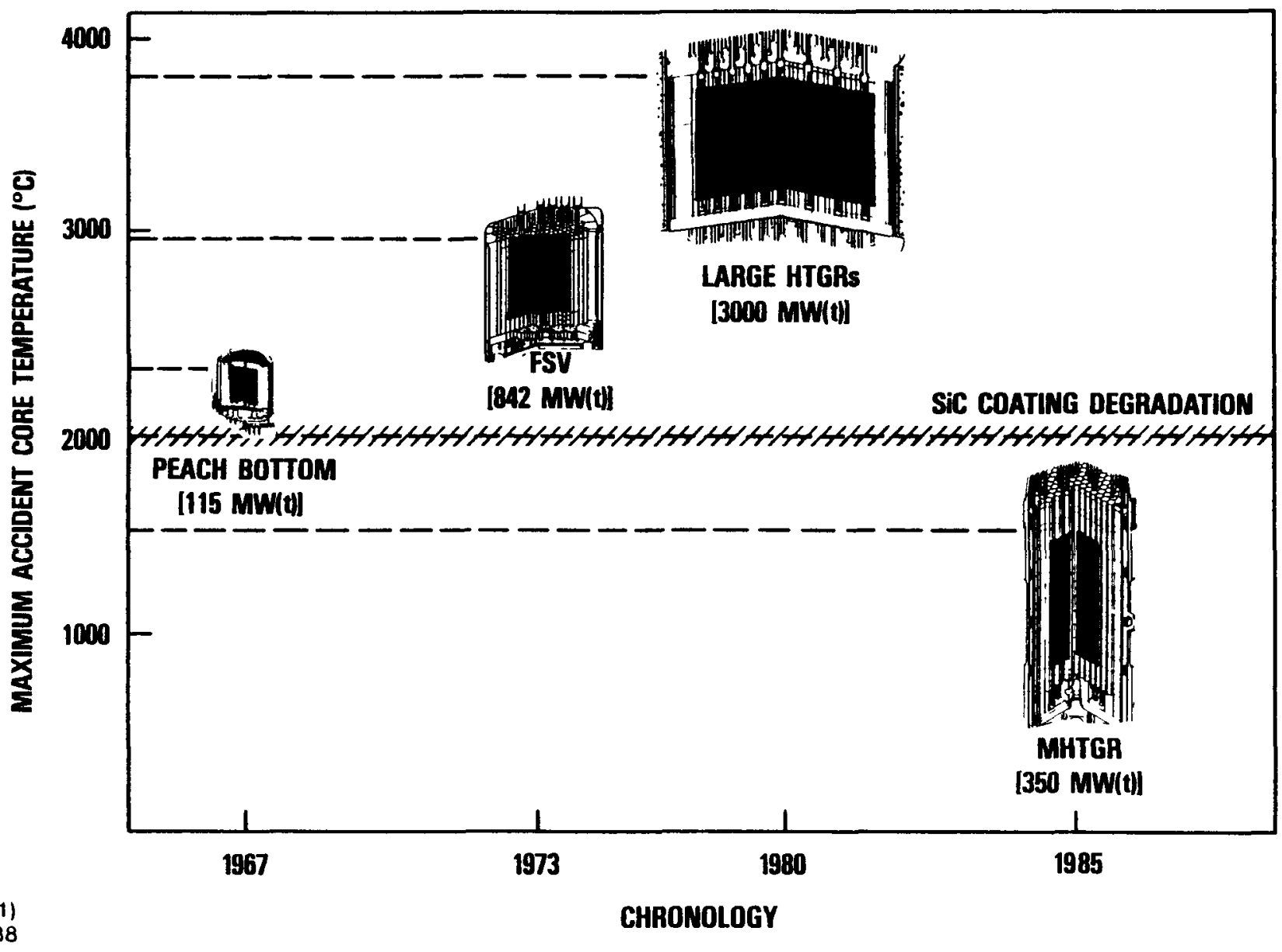

Figure 1. Size and Geometry of Modular HTGR Precludes Failure of Ceramic Coated Fuel Particles 


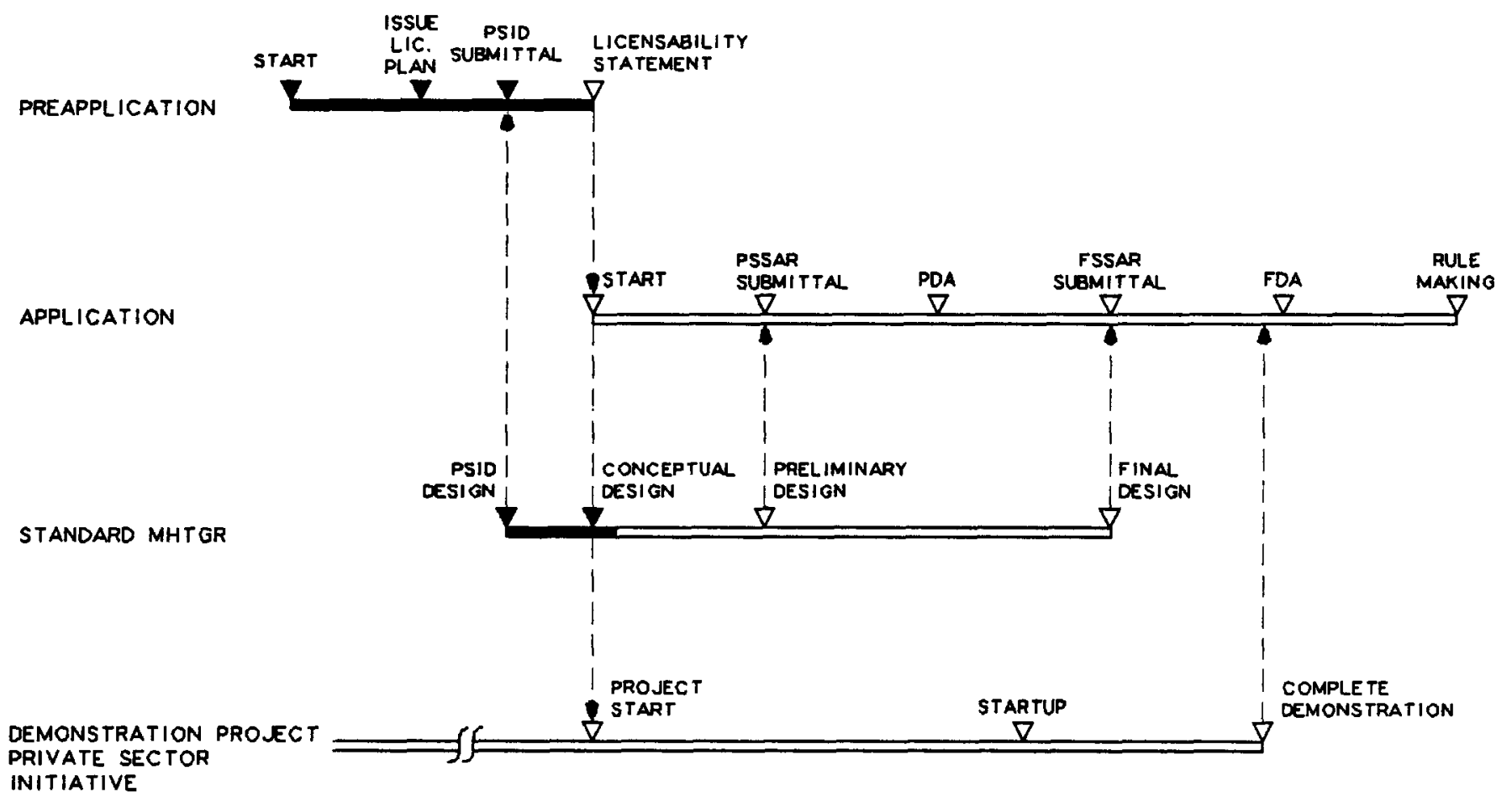

Figure 2. Logic for HTGR Licensing Activities 


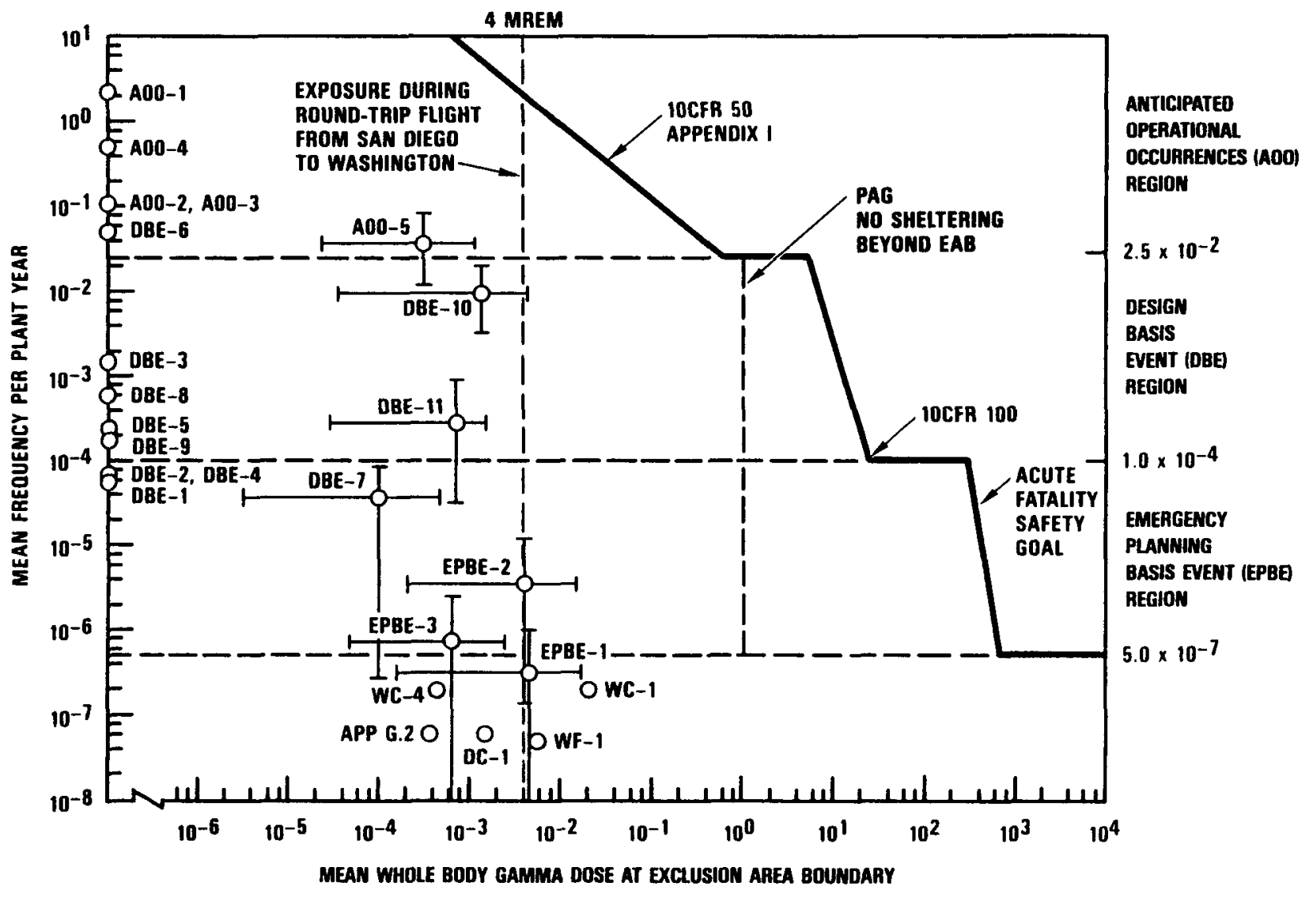

Figure 3. MHTGR Meets Licensing Requirements with Large Margins 